\title{
Percepções de estudantes que visam ao ensino superior sobre medicalização e saúde mental
}

\author{
Perceptions on medicalization and mental health by \\ students aiming at university education
}

\author{
Emilia Suitberta de Oliveira Trigueiro', Maria Isabel da Silva Leme ${ }^{2}$ \\ 'Autora para correspondência. Instituto Federal do Ceará. Crato, Ceará, Brasil. emiliatrigueiro@hotmail.com \\ ${ }^{2}$ Departamento de Psicologia da Aprendizagem, do Desenvolvimento e da Personalidade, Instituto de Psicologia da Universidade de São Paulo. \\ São Paulo, São Paulo, Brasil. belleme@usp.br
}

\begin{abstract}
RESUMO I O aprimoramento cognitivo farmacológico refere-se ao uso de medicamentos por pessoas saudáveis para melhorar o funcionamento do cérebro e o desempenho cognitivo. Um dos medicamentos mais utilizados no Brasil com essa finalidade é o Cloridrato de Metilfenidato, que tem sido consumido por estudantes de ensino médio e superior com o objetivo de aumentarem a capacidade produtiva para cumprirem prazos e metas. Considerando que essa prática está se disseminando na sociedade, foi realizado um estudo com o objetivo de caracterizar a percepção de alunos do $3^{\circ}$ ano do ensino médio de uma escola profissionalizante da cidade de Juazeiro do Norte (CE) sobre o uso de medicamentos para aprimoramento cognitivo. A pesquisa foi realizada por meio de dois grupos focais com a participação de 13 alunos. Os resultados apontaram que os medicamentos para aprimoramento cognitivo foram vistos inicialmente como algo positivo, que poderia ser usado às vésperas do vestibular e para ajudar nos momentos de pressão por parte dos pais e da escola. No entanto, quando tiveram a oportunidade de refletir sobre o tema, os alunos conseguiram perceber os fatores envolvidos na adesão ao uso de substâncias e - que leva os estudantes a consumi-las. Concluiu-se, neste estudo, que é importante compreender a percepção dos jovens sobre esse tema para que se possa planejar e orientar futuras intervenções.
\end{abstract}

PALAVRAS-CHAVE: Medicalização; Aprimoramento cognitivo farmacológico; Doping intelectual.

\begin{abstract}
Pharmacological cognitive enhancement refers to the use of drugs by healthy individuals aiming at enhancing the brain functioning and the cognitive performance. One of the widely used drugs in Brazil with these aims is Methylphenidate Hydrochloride which has been used by high school and college students aiming at enhancing their productive capacity to meet deadlines and goals. Considering the dissemination of this practice in society, this study was held aiming at characterizing the perception of high-school final-year students from a vocational school in the city of Juazeiro do Norte (CE) on the use of drugs for cognitive enhancement. The research was conducted through two focus groups with the participation of 13 students. Results indicated that enhancement drugs were deemed initially as something positive that could be used on the eve of entrance examinations and help in moments of pressure from parents and school. However, when faced with the opportunity to reflect on the theme, students could perceive the factors involved in the adhesion to the use of substances and what drives them to its consumption. It is concluded in this study that it is important to understand youngsters' perceptions on this theme so that future interventions can be guided and planned.
\end{abstract}

KEYWORDS: Medicalization; Pharmacological cognitive enhancement; Intellectual doping. 


\section{Introdução}

A escola tem a função de socializar os indivíduos, incutir cultura e valores morais, transmitir os conhecimentos científicos acumulados pela humanidade e preparar as pessoas para trabalharem e contribuírem para o desenvolvimento da sociedade. Devido a essa grande importância, todos os brasileiros entre 4 e 17 anos de idade devem estar matriculados na escola, seja na educação básica, no ensino fundamental ou no ensino médio.

ensino médio, particularmente, é uma etapa de formação situada entre o final do ensino fundamental e 0 acesso ao ensino superior. Esta etapa tornou-se obrigatória somente em 2009, e no decorrer dos anos acumulou desafios e contradições, sendo os principais o acesso dos alunos (que ainda não é universal), a evasão (que é muito grande), a falta de identidade (o ensino deve focar no acesso ao ensino superior ou na preparação técnica para o trabalho?) e a baixa qualidade, expressa nos resultados das avaliações.

Dentre as atuais funções do ensino médio, uma das mais valorizadas pelos alunos e pelas instituições é a preparação para $\circ$ ensino superior. $O$ acesso se dá pelo vestibular, que classifica apenas alguns dos inscritos. Os motivos de não aprovação podem ser: (a) preocupados com o sucesso no exame, os alunos ficam com receio de não serem bem-sucedidos, o que leva ao aumento de sintomas de ansiedade e estresse e ao consequente mau desempenho na prova; (b) pode haver um histórico de reprovações ou de baixo aproveitamento no ensino fundamental e médio, devido a um sistema escolar excludente.

O aumento dessas expectativas em relação à aprovação no exame pode resultar em elevação de sintomas de ansiedade e estresse, conforme mencionado acima. Além disso, a sensação de que a escola pode não ter preparado bem o suficiente, aliada ao receio de ser reprovado e ter que dedicar mais um ano de sua vida a essa preparação, ou de desistir de um curso superior e ingressar no mercado de trabalho, podem fazer com que jovens do ensino médio recorram a diferentes estratégias para ter sucesso, sendo uma delas o aprimoramento cognitivo farmacológico.
Existem diversas maneiras de melhorar o funcionamento cerebral, tais como ambientes estimulantes, técnicas de autorregulação da aprendizagem, dietas alimentares, vitaminas, exercícios físicos e psicofármacos. O uso de medicamentos por pessoas saudáveis para melhorar o funcionamento do cérebro e aprimorar o desempenho cognitivo pode ser chamado de aprimoramento cognitivo farmacológico, ou de doping intelectual. Uma razão para o uso desses medicamentos é que supostamente eles têm uma ação mais rápida do que a mudança na estratégia de estudo, por exemplo, pois podem induzir modificações nas sinapses envolvidas nas redes cognitivas.

Um dos medicamentos mais utilizados no Brasil com essa finalidade é o Cloridrato de Metilfenidato, comercializado com o nome de Ritalina $\AA$ ou Concerta $\AA$. Ele tem sido utilizado por estudantes, tanto universitários quanto alunos de ensino médio, e por empresários e profissionais da saúde com a finalidade de aumentar a capacidade produtiva para cumprir prazos e metas. Essa substância é bastante conhecida do público universitário, pois $94,23 \%$ dos estudantes de medicina do Centro Universitário de Volta Redonda (RJ) informaram já terem ouvido falar dela e $63 \%$ conheciam seu mecanismo de ação (Carneiro et al., 2013), 35,5\% dos estudantes da Universidade Federal da Bahia conheciam outros estudantes que faziam uso e $7,5 \%$ sabiam onde comprar o medicamento sem receita médica (Cruz et al., 2011).

Cesar et al. (2012), em pesquisa com universitários de instituições públicas e privadas das 27 capitais brasileiras, encontraram maior prevalência de usuários do metilfenidato nos primeiros anos de graduação, nos cursos da área de humanas e de instituições privadas. $O$ uso também foi mais frequente entre aqueles das regiões centro-oeste e sul do país, bem como entre os que moravam em república ou alojamento estudantil.

Tsuda e Christoff (2015) apontam ainda que 3,13\% dos estudantes de medicina participantes de sua pesquisa relataram intercorrências resultantes do uso do metilfenidato, tais como problemas de saúde, social, legal ou financeiro, bem como relataram que $\circ$ uso da substância suscitou a preocupação de pessoas próximas. Além disso, 1,56\% também ad- 
mitiu não ter sido bem-sucedido nas tentativas de controlar, diminuir ou mesmo parar o consumo. Mas - restante dos alunos não considerou seu uso problemático e nem associou qualquer prejuízo relacionado ao consumo da substância, alegando que nunca tiveram qualquer dificuldade em parar. Entretanto, é preciso cuidado com o uso dessas drogas, pois elas não foram avaliadas suficientemente para serem usadas com esse objetivo, sem esquecer as implicações éticas e sociais sobre seu uso (Machado \& Toma, 2016).

O tema é polêmico e suscita muitos debates. Os defensores da prática como, por exemplo, Greely et al. (2008), argumentam que o cloridrato de metilfenidato é uma droga segura com poucos efeitos colaterais e que a utilização para aperfeiçoamento cognitivo é um objetivo louvável e uma escolha pessoal. Para isso, seria necessária apenas uma política de saúde formada por uma variada fonte de recursos científicos, profissionais, sociais e educacionais, somada à legislação. Em oposição, outros pesquisadores como, por exemplo, Farah e Wolpe (2004) alegam que seria antiético melhorar deliberadamente a concentração e memória de um indivíduo, além de questionarem as vantagens do metilfenidato, uma vez que estas são mínimas e os riscos do uso em longo prazo não são conhecidos.

Como essa prática tem ganhado cada vez mais adeptos e o acesso a esse medicamento é facilitado, é necessário aprofundar o entendimento desse fenômeno, principalmente em relação a uma população vulnerável, como são os adolescentes, particularmente aqueles que estão em uma fase decisiva de suas vidas, como é o caso da seleção para o ensino superior.

Também deve ser considerado que a origem deste problema, que pode ter consequências para a saúde mental dos futuros profissionais, pode residir nas características dos processos seletivos para ingresso no ensino superior, visto que devido às pressões por resultados imediatos, os pais, as escolas e a sociedade em geral têm colocado grande pressão sobre os adolescentes para que sejam bem-sucedidos no vestibular. Quando isso não acontece, esses jovens muitas vezes procuram cursinhos pré-vestibulares, a fim de se prepararem melhor. Entretanto, junto com a preparação vem, mais uma vez, uma grande pressão, o que pode levar os jovens a buscarem outros meios para alcançarem o sucesso, como os aprimoradores cognitivos farmacológicos. E quando acreditam que lograram sucesso devido ao uso destes medicamentos podem continuar com essa prática, colocando em risco tanto a saúde física quanto a mental.

Nesse contexto, para seu desenvolvimento, esta pesquisa partiu do seguinte problema: qual a percepção dos estudantes do $3^{\circ}$ ano do ensino médio sobre o uso de medicamentos para aprimoramento cognitivo? No intento de investigar essa questão, definiu-se como objetivo caracterizar a percepção de alunos do $3^{\circ}$ ano do ensino médio de uma escola profissionalizante da cidade de Juazeiro do Norte (CE) sobre o uso de medicamentos para aprimoramento cognitivo.

O interesse por esse tema se dá também devido ao aumento da prescrição desse tipo de medicamento para crianças e adolescentes, entre 6 e 16 anos, bem como o uso indiscriminado que pode estar sendo feito por jovens para potencializarem seu desempenho nos estudos, sem que haja dados reais sobre este uso. Sabe-se que esses medicamentos podem ter como efeito imediato o aumento da concentração, mas em longo prazo podem causar supressão do crescimento, aumento da pressão sanguínea, episódios psicóticos, entre outros sintomas (ANVISA, 2012). Além disso, se perceberem o uso como fator de sucesso, esses jovens podem permanecer apelando para este tipo de solução quando se sentirem inseguros sobre o resultado que obterão na universidade.

Acredita-se que conhecer a percepção dos jovens sobre o doping intelectual pode viabilizar práticas preventivas em relação ao uso, por isso, a pesquisa se torna relevante (a) para os jovens, em virtude da importância do tema na atualidade e do espaço que ele tem ganhado no contexto social, com grandes possibilidades de acesso a medicamentos; (b) para as escolas, que poderão rever suas práticas produtoras de fracasso escolar, o que pode levar alguns alunos ao uso de medicamentos; (c) para a sociedade, pois buscará desmitificar a ideia de que os problemas cotidianos podem ser resolvidos com pílulas e que o cérebro humano sempre pode atingir níveis mais altos. 
Método

Esta pesquisa foi realizada por meio de dois grupos focais com a participação de 13 alunos de uma escola profissionalizante da cidade de Juazeiro do Norte (CE).

Os grupos focais consistem em uma técnica de pesquisa que coleta dados por meio das interações grupais ao se discutir um tópico específico sugerido pelo pesquisador. É um recurso para compreender o processo de construção das percepções, atitudes e representações sociais de grupos humanos. Segundo Gondim (2003), a unidade de análise do grupo focal é o próprio grupo, pois quando uma opinião é manifestada, mesmo não sendo compartilhada por todos, para efeito de análise e interpretação dos resultados, ela é referida como do grupo, numa coprodução de sentidos.

Esta pesquisa pode ser configurada como uma pesquisa intervenção, visto que contemplou uma dimensão ética, uma vez que envolveu intervenções marcadas por posicionamentos de orientação e problematização da temática junto aos participantes. Estes participantes, por sua vez, além de participarem da pesquisa como sujeitos ativos puderam se educar, se organizar, e se apropriar de um saber construído coletivamente (Schmidt, 2006).

Definida a instituição que participaria da pesquisa, foi feito o primeiro contato e entregue uma carta de apresentação da pesquisa, onde foram explicados os objetivos. Posteriormente foi feito o contato com os pais dos alunos, por meio de uma carta descrevendo o estudo a ser realizado, seus riscos e benefícios, e informações para o envio à pesquisadora do Termo de Consentimento Livre e Esclarecido assinado no caso de concordância com a participação de seus filhos no estudo. Já em sala de aula, os alunos assinaram o Termo de Assentimento Livre e Esclarecido. Fizeram parte do estudo os alunos presentes em sala de aula no dia, que concordaram em participar e que trouxeram o Termo de Consentimento Livre e Esclarecido assinado pelos pais.

No primeiro contato com a turma, a pesquisadora se apresentou e convidou os alunos a participarem de grupos de discussão sobre o que os jovens pensam sobre a pressão social para passar no vestibular e os diferentes meios utilizados para aumentar o rendimento nos estudos. Na instituição há 4 turmas de $3^{\circ}$ ano do ensino médio, e foram indicadas 2 turmas para participar do estudo. Dos 49 alunos das duas turmas presentes em sala de aula, 15 se voluntariaram a participar.

Os encontros foram agendados, segundo a disponibilidade da instituição, para a semana seguinte. Eles ocorreram em uma sala designada pela direção da instituição e em horário de aula. Ou seja, os outros alunos da turma permaneceram assistindo à aula enquanto os que se se voluntariaram participavam do grupo. No dia e horário acordado os alunos foram convidados a se reunirem com a pesquisadora. No momento da realização dos grupos, além da pesquisadora, estava presente uma observadora que foi responsável pela gravação e por anotar os nomes dos que se manifestaram, para posterior identificação. As reuniões dos dois grupos foram gravadas com a autorização dos participantes e depois transcritas na íntegra.

Dos 15 alunos que se voluntariaram inicialmente, apenas 9 compareceram ao primeiro encontro. Inicialmente foi informado a eles do que tratava a pesquisa, e foi solicitada a assinatura do Termo de Assentimento Livre e Esclarecido. Também foi solicitado que eles respondessem a um questionário que objetivou caracterizar a amostra. Após essa parte inicial, a pesquisadora deu início às discussões. Nesse primeiro dia foram debatidos os seguintes temas: as definições de medicalização e de medicamentalização, a medicalização da vida, a relação entre o uso abusivo das tecnologias e a depressão, a medicalização da aprendizagem, o aprimoramento cognitivo farmacológico, a pressão sobre o jovem para ser aprovado no vestibular, o doping intelectual e o vestibular.

O segundo encontro ocorreu 2 dias após o primeiro, também em horário determinado pela direção. Participaram desse encontro 5 alunos, sendo que apenas um deles tinha participado do primeiro encontro, pois os demais estavam em uma atividade avaliativa. $O$ encontro abordou a discussão dos seguintes temas: recapitulação do encontro anterior, o sistema de ensino brasileiro, a pressão em relação ao vestibular e o aprimoramento cognitivo farmacológico. Logo após, houve a entrega de um folder 
elaborado pelas autoras contendo informações a respeito dos riscos do consumo desses medicamentos e estratégias para melhorar o aproveitamento nos estudos, e por fim o fechamento do grupo. Esse grupo também teve duração de uma hora.

Após a finalização dos grupos foi feita a transcrição da gravação e a identificação das falas de cada participante. Para fins de organização e com $\circ$ intuito de não identificá-los, as fichas dos participantes foram colocadas em ordem alfabética e a cada uma foi atribuído um nome fictício. Nos relatos que serão apresentados adiante, foram feitas leves correções para facilitar a leitura.

Ressalta-se que este trabalho faz parte da tese de doutorado da primeira autora sob orientação da segunda, portanto, para maiores informações sobre os procedimentos metodológicos consultar Trigueiro (2017).

O projeto foi aprovado pelo Comitê de Ética do Instituto de Psicologia da Universidade de São Paulo e aprovado em 08-06-2015 sob o CAAE 42211115.8 .0000 .5561$.

\section{Resultados}

A partir do questionário de caracterização do grupo foram obtidos os seguintes dados: nenhum dos alunos recebe ou recebeu em algum momento prescrição para usar o cloridrato de metilfenidato; um aluno conhece uma pessoa que tem prescrição para usar cloridrato de metilfenidato; nenhum aluno experimentou cloridrato de metilfenidato com a finalidade de melhorar o aproveitamento nos estudos; um aluno conhecia alguém que experimentou o medicamento com esta finalidade. Finalmente, quando questionados se já tinham lido ou ouvido falar sobre o cloridrato de metilfenidato usado com esta finalidade, 5 alunos responderam afirmativamente.

Após a apresentação dos participantes do grupo e da metodologia que seria utilizada, a pesquisadora leu a seguinte definição de medicalização:

Pesquisadora: Dá-se o nome de Medicalização ao processo por meio do qual são deslocados para
- campo médico problemas que fazem parte do cotidiano dos indivíduos. Por exemplo, transformar sensações físicas e psicológicas normais como insônia e tristeza em sintomas de doenças, como Distúrbio do Sono e Depressão. Significa transformar situações comuns como a tristeza, afinal todo mundo fica triste,

e determinar que, na verdade, toda tristeza é uma

Depressão, sendo que Depressão é uma doença e não algo que acontece o tempo inteiro com todo o mundo. Dentro, ainda, desse processo, existe um outro, denominado Medicamentalização que é o uso excessivo

de medicamentos para o alivio dessas sensações que não são doenças, mas que têm sido consideradas como

tal. Por exemplo, às vezes temos insônia se estamos preocupados com alguma coisa, se temos uma prova no dia seguinte e não conseguimos dormir. Antigamente as pessoas costumavam tomar um banho, um chá, apagavam as luzes e tentavam dormir. Hoje em dia, como as pessoas fazem? Elas tomam um calmante, tomam algum remédio para conseguir dormir. Ou ainda, mais um exemplo, quando éramos crianças

e tínhamos uma gripe, alguém fazia um chá, um

banho morno. Hoje em dia corremos à farmácia e já compramos quatro ou cinco remédios.

Em seguida a essa definição, os alunos puderam relatar exemplos de como isso ocorre em seu cotidiano:

Lucas: [...] Acho que pela pressão do dia a dia, as pessoas acabam se achando mais tristes, mais depressivas, sem motivos para viver. Já vi casos, na minha família mesmo, onde o sujeito diz, "eu trabalho todo dia, das $7 \mathrm{~h}$ às $5 \mathrm{~h}$ da tarde, à noite eu tenho que estudar até às $10 \mathrm{~h}$. Não consigo me divertir. $\mathrm{O}$ dinheiro só dá para pagar as contas." Por isso, as pessoas acabam ficando tristes progressivamente e achando que é depressão. Então ela vai tomando calmantes, remédios para depressão [...] Um outro bom exemplo é o uso da maconha. Algumas pessoas usam a maconha para estar em "outro plano" e em busca desse alívio do dia-a-dia, dessas tristezas, de falta de dinheiro, de ter que trabalhar todo dia para ganhar aquilo. (Masculino, 17).

Mateus: Alguns remédios tratam doenças, mas eles também podem gerar dependência em quem consome.

Algumas pessoas têm vícios em drogas ilícitas, mas remédios também são drogas, só que lícitas. Por exemplo, pessoas que tomam remédio para qualquer dor de cabeça que têm e sempre retornam na mesma dor de cabeça. Eu prefiro fazer de outra forma, não tomar remédio e me deitar, relaxar; porque 
ficamos dependentes dos remédios. $E$ essa questão da depressão, está acontecendo muito em jovens que deveriam ser os mais alegres, mas hoje os jovens são mais tristes, revoltados, mais cansados, e isso aumenta também o número de suicídios. As estatísticas dizem que o número de suicídios hoje é muito maior do que de dez anos atrás, mesmo em cidades pequenas, como a nossa. Se pegarmos um caso de suicídio e investigarmos a fundo, descobriremos que aquela pessoa estava triste, mesmo não demonstrando isso, muitas vezes. Além disso, outras coisas podem influenciar, como o estilo de vida, a jornada de trabalho, muitos fatores. (Masculino, 17).

Júlia: Não acho que a forma certa de tratar pessoas com distúrbios psicológicos seja com medicação, internação. Não é certo dopar outra pessoa porque ela está com distúrbios ou porque ela imagina coisas. Às vezes penso que só o apoio da família já resolveria.

(Feminino, 17).

Esses depoimentos mostram que esses jovens percebem esse fenômeno ocorrendo no cotidiano e seu risco de comprometimento à vida das pessoas. Os estudantes também fizeram uma relação entre o uso abusivo das tecnologias e a depressão, e ainda associaram questões políticas e sociais com alguns sintomas que são cada vez mais frequentes:

Mateus: Achei a fala dela muito interessante, porque hoje a tecnologia avançada, que faz Smartphone, por exemplo, pode regular as nossas relações pessoais. Por exemplo, às vezes um grupo de amigos sai, fica todo mundo no celular ninguém conversa com ninguém.

Houve um episódio em que uma colega estava com fone de ouvido e eu não conseguia falar com ela e tive que mandar uma mensagem para ela avisando que eu a estava chamando para que ela pudesse ver. Ou seja, que influência isso tem, de repente, numa depressão, já que uma rede social ou qualquer coisa desse tipo não vai suprir a necessidade de uma conversa cara-a-cara com você... é bom, mas tem que tomar cuidado, porque ela tem um lado negativo. Eu me acho muito chato. Se

é para sair em um grupo de amigos e todos ficarem no celular, é melhor nem sair, fica cada um na sua casa. Então fica insuportável. Porque as pessoas pensam que estão lá no Face, e acabam esquecendo de conversar e ao final você vai ficar com um vazio interior, já que não tem relações corpo a corpo, olho a olho. As novas gerações não desenvolvem bem esse contato, é muito triste isso. (Masculino, 17).
Lucas: Acho que isso parece o caso de uma colega de turma. Ela tem muita dificuldade em responder quando é chamada porque cria, dentro da mente dela, histórias e histórias, fica pensando em desenho [animado]. Hoje ela parece estar melhorando, pois nós estamos chamando a atenção dela, mas antes era assim. Ela não prestava atenção em nenhuma das nove aulas que a gente tinha, ela pensava em qualquer outra coisa, menos na aula. Nem no estágio ela nos dava atenção.

A gente podia falar com ela mil vezes, mas se ela estivesse ouvindo música ela já estava imaginando um vídeo clipe para a música. É muito complicada essa questão. Eu fui perguntar para ela porque ela achava que se comportava dessa forma. Ela pensa que isso é resultado de ficar muito tempo em casa e não ter uma boa relação com seus pais. Ela diz que os pais querem fazer da vida dela um inferno, que ela passou a maior

parte da infância dela dentro do quarto escutando música, desenhando, criando histórias entre outras coisas, mas nunca na companhia de outras pessoas. Isso é reforçado por ela morar muito longe de todos. Então, podemos trazer isso para os dias de hoje, sobre a questão dos meios de comunicação, mesmo que isso de "não responder para as pessoas quando você está navegando na internet" não seja uma doença, pode gerar uma. Por exemplo, eu ficava muito tempo no celular, e quando eu ficava muito tempo no celular eu ficava pensando nisso, em quem estava lá ou não, no

Facebook, WhatsApp, essas coisas. $E$ isso me fazia não prestar atenção em ninguém que estava ao meu lado. E isso estava gerando um "Déficit de atenção" em mim. Agora, quase não uso o celular, se eu fico em casa eu deixo dentro de uma gaveta, eu falo com as pessoas dentro e fora de casa também. Pode ser que na hora não, mas depois isso vai gerar um incômodo.

(Masculino, 17).

Mateus: $E$ também tem um fator de classe, num sentido de classe social. Hoje, a maioria dos pais tem criado seus filhos sem brincar na rua e brincando com aparelhos tecnológicos, então uma criança de 9 anos tem um tablet, um computador, um Xbox. $E$ é também

uma coisa do grupo social, por exemplo, todos os amigos de um grupo tem os mesmos aparelhos e se uma das crianças não tem o que as outras têm, essa criança vai pedir para os pais, porque, inclusive, essa posse é necessária para ela ser aceita no grupo. Isso faz com que a criança fique hiperativa, dependente daquilo. Além disso, são esses hábitos que criam uma cultura de individualismo. Então, acredito que a questão social influencia muito, nosso lugar social, nosso estilo de vida. (Masculino, 17). 
No momento seguinte os alunos levantaram a questão sobre como a falta de interesse de alguns alunos pela escola está associada à medicalização da aprendizagem:

Júlia: [...] Eu acho que a escola é muito chata, mas quanto mais você estuda, mais fácil fica. Eu gosto de livros de romance e com essa leitura eu não me sinto com sono, o que é muito diferente com história. É como quando você não quer fazer uma coisa porque é chata, como estudar, mas o joguinho é legal, então presta-se atenção no joguinho. Eu acho que é mais ou menos isso, não doença. (Feminino, 17).

Mateus: $E$ vai bloqueando a mente para algumas coisas... E para outras vai se abrindo... Como você disse, ele tem atenção para o jogo, mas não tem para a aula, então a aula já vai sendo bloqueada. A mente

comanda todo o corpo, e o psicológico tem muita influência sobre a nossa vida. É como quem diz que não entende matemática, isso não é necessariamente

verdade, muitas vezes você colocou na cabeça que não entende matemática. Eu acho que isso não é uma doença, isso é o psicológico sim, mas não uma doença.

(Masculino, 17).

Da discussão sobre a medicalização da aprendizagem passou-se à discussão do aprimoramento cognitivo farmacológico e sua relação com o vestibular. Os alunos foram convidados a refletir sobre quais impactos poderia haver caso alguns concorrentes fizessem uso dessa prática:

Lucas: No meu caso eu não toparia fazer isso. Não gosto. Mas se eu estiver competindo com alguém que tomou e em quem esse medicamento funciona... Por exemplo, se tem dez vagas e quinze concorrentes, cinco estão fazendo uso das drogas e os outros cinco, que estudaram pra caramba, que passaram talvez anos tentando alcançar aquela nota, pode ficar em décimo lugar porque uma pessoa tomou um remédio e você não? Eu acho isso injusto. (Masculino, 17).

Lucas: Não vale a pena, mas muita gente toma por pressão em casa. Os pais querem que o filho passe em medicina, então ele presta vestibular para medicina e ele não quer decepcionar ninguém... Muitos jovens sofrem uma pressão dos pais por desempenho escolar ou no vestibular, e sentem muita responsabilidade em não decepcionar os pais. Em resposta a isso, esses jovens vão fazer de tudo para não decepcionar; e aí você sabe que ele não vai passar só estudando, ele vai buscar medicamentos. $E$ também outras influências em casa, se você terminou o ensino médio e agora vai só estudar e não trabalhar, muitas vezes os pais ficam

incomodados. Aí, para não sofrer mais pressão do que já se sofre em casa, as pessoas recorrem a esses remédios. $E$ aí, às vezes, ele passa e não é por ele, mas para dar orgulho aos pais. (Masculino, 17).

Lucas: Por isso eu acho importante a gente sempre questionar o uso de drogas, principalmente ilícitas.

Existem muitas campanhas sempre mostrando as consequências desses abusos e acho que o mesmo deveria acontecer a respeito desse doping intelectual. Porque as pessoas que estão se drogando para passar em tal curso, muito provavelmente não conhecem as consequências das coisas que estão tomando, conhecem apenas as vantagens. Eu só vi vantagens, a princípio. Você toma para se concentrar e se concentra, de fato.

Mas você nunca sabe se está de fato aprendendo

e, como a professora disse, não tem garantia de resultado. $E$ ainda tem gente que consegue se concentrar

naturalmente, consegue estudar naturalmente até melhor do que quem está se concentrando por causa de remédios. É necessário ter campanhas informativas sobre o uso dessas drogas, porque quem não conhece

os efeitos colaterais, só vai ver vantagem. Se meus pais me forçassem a fazer algo, e eu não tivesse saída eu procuraria os remédios - se eu soubesse só das vantagens e não das consequências. (Masculino, 17).

Lucas: Você pode se concentrar sim, mas talvez não nos estudos, necessariamente. Que é a pergunta inicial,

sobre estar concentrado nos jogos e não estar nos estudos. Acredito que todo ser humano tem tendência a se concentrar em coisas que ele gosta. Se ele gosta de estudar, vai se concentrar nos estudos, se ele gosta de ler, como ela, romances, vai conseguir se concentrar nisso. Então essa questão de se concentrar ou não nos estudos... Se você não gosta de estudar, meu bem, não vai rolar. (Masculino, 17).

A partir dessas informações eles puderam fazer extrapolações, como pode ser visto a seguir:

Lucas: Além disso, isso deve movimentar todo um mercado ilegal, porque sempre vai ter alguém para vender drogas; deve envolver muito dinheiro. Então o problema não está só em quem toma, mas também em todo esse mercado que se movimenta. $E$ as pessoas que pertencem a ele não estão nem aí se você vai ter uma reação alérgica, se vai morrer ou não. Eles só querem vender, e vender caro. (Masculino, 17) 
Outro ponto interessante foi levantado por um dos alunos em relação ao sistema educacional brasileiro e sua estrutura de funcionamento:

Fernando: Eu vejo toda essa situação num sentido bem educacional. O sistema educacional brasileiro, que acha que você precisa assistir muita aula para aprender e na verdade isso está errado, já que esse

é um processo passivo e o estudo, para dar certo, precisa ser acompanhado mais individualmente, para ser ativo. Outra coisa é um consenso brasileiro de que estudar é chato, quem estuda é chato. Aí, por exemplo, existe um exame chamado PISA, que é como o ENEM, mas mundialmente. $O$ Brasil participa desse exame e, quanto mais países entram nesse ranking, mais o Brasil cai de posição. $O$ sistema educacional brasileiro não funciona. Em outros países o que vigora é o sistema educacional integral, onde as crianças têm aulas de manhã e durante a tarde tem atividades para revisar

e reforçar o que foi aprendido no outro período, enquanto aqui foi implementado o sistema integral com aulas durante todo o dia. Isso torna o aprendizado impossível; tudo que estamos aprendendo aqui e agora, por exemplo, está no sistema límbico, no espaço da memória curta e, quando formos dormir, o que está aqui vai ser "filtrado" e o que for de fato importante, vai ser levado para o córtex. Para que esse transporte de informação aconteça, é necessário descanso.

(Masculino, 18).

Após essa reflexão o primeiro encontro foi encerrado, e todos foram convidados a retornarem no momento agendado para o segundo encontro.

O segundo encontro iniciou-se com uma recapitulação do encontro anterior, já que apenas um dos participantes estivera presente. A partir daí foram discutidos o sistema de ensino brasileiro e o vestibular. Os alunos foram questionados sobre o fato de ser aplicada uma prova única para os alunos de todo o Brasil, a fim de avaliar o que eles aprenderam nos três anos do ensino médio. A esse questionamento, eles responderam:

Nicolas: A prova vai mostrar o conteúdo que foi absorvido e como foi a base de estudo daquela pessoa. Se ela não teve uma base de estudo satisfatória ela vai sentir dificuldades, pois não aprendeu tudo que deveria ter aprendido. (Masculino, 18).
Fernando: Acredito que é o mesmo conteúdo, mas com metodologia diferente. Os jovens deste outro colégio focam muito no vestibular. Por isso acho que deveria ser observado a realidade de cada ambiente, de cada escola. Uma escola com menos recursos pode ter alunos com um desempenho mais baixo. Isso tem influência dos investimentos governamentais, da administração pública. Pensando nisso é injusto que haja uma mesma prova para realidades tão diferentes. (Masculino, 18).

Fernando: Sem contar que o aluno da escola privada está focado em desenvolver habilidades específicas para o vestibular, enquanto o de uma escola profissional desenvolve outras habilidades que não vão se refletir no vestibular. (Masculino, 18).

Os alunos também foram convidados a discorrer sobre a pressão em relação ao vestibular e como isso pode induzir ao uso de aprimoradores cognitivos:

Pesquisadora: [...] Quando você considera esse processo seletivo justo, pois todos estão fazendo a mesma prova, para os que não passam fica a conclusão de que eles não se esforçaram e não estudaram suficiente. Não é? [...] Vocês acham que os estudantes que se sentem mais pressionados poderiam mais provavelmente recorrer a esses medicamentos ou não?

Nicolas: Acho que sim, porque na sua cabeça você vai ouvir essa necessidade e, de uma certa forma, vai buscar o melhor resultado possível independente dos meios. (Masculino, 18).

Também foi realizada uma discussão sobre a possível associação entre diferentes tipos de escolas, diferentes cidades e a tendência ao uso dessas substâncias:

Nicolas: Eu acho que em outros lugares pode haver mais informação sobre esses medicamentos do que em nossa cidade, pois eu, particularmente não o conhecia. Acho que também pode acontecer de a pessoa saber sobre $o$ assunto e assumir a consequência sobre 0 uso dessas drogas. (Masculino, 18).

Germana: Temos que dar conta de muito conteúdo. A gente tem a pressão de estar sempre preparado, de saber tudo. Acho que é por isso que alguns estudantes podem recorrer a esses medicamentos, principalmente os que não tem o hábito de estudar e deixam tudo para a última hora. (Feminino, 17). 
Fernando: Uma pressão familiar, da escola. Você tem que passar no vestibular, é o que tem que acontecer. Acontece que por mais que você estude, não tem lugar para você lá. (Masculino, 18).

Pesquisadora: [...] Vocês acham que nas cidades maiores, essa pressão seria maior ou menor do que nas cidades menores?

Fernando: Acho que nas cidades maiores a pressão é maior. (Masculino, 18).

Pesquisadora: Por quê?

Fernando: Não sei... Acho que o crescimento e desenvolvimento das cidades e a necessidade de mão-de-obra vão fazendo com que o movimento da cidade seja mais acelerado. Então você precisa ter essa preparação para se inserir no mercado de trabalho de forma muito mais rápida do que nas cidades menores.

(Masculino, 18).

Heitor: A concorrência é grande tanto no vestibular quanto no mercado de trabalho, porque você precisa se destacar para ter seu lugar garantido. Sinal dessa grande concorrência que você está falando. (Masculino,

Nicolas: Acredito também que em grandes cidades tenha um acesso mais fácil a esse tipo de medicamento.

(Masculino, 18).

Fernando: Tem pessoas que vivem numa realidade diferente da nossa, onde o principal é ganhar dinheiro.

$\mathrm{Se}$, por exemplo, uma pessoa dessas quer passar em um concurso, mas não consegue ter muita atenção nos estudos, pode ser que caia nessa de tomar esse tipo de remédio. (Masculino, 18).

Germana: Uma pessoa pode dizer que não vai usar isso porque tem efeitos colaterais e outros que aceitam correr os riscos, porque acham que será melhor assim, pois tem benefícios. (Feminino, 17).

André: Pode ser falta de orientação também; eu imagino que a maioria das pessoas que toma essas drogas, toma porque não teve orientação suficiente para não tomar. (Masculino, 17).

Nesse momento a pesquisadora apresentou aos alunos os dados coletados na pesquisa quantitativa de Trigueiro (2017), com o intuito de confrontar a per- cepção desses alunos com a que havia sido expressa nos questionários. Para isso, foram lidas algumas respostas e os alunos puderam comentá-las.

Pesquisadora: "Eu não concordo com o uso desses medicamentos porque é isso que as indústrias

farmacêuticas querem. Esse mercado ganha milhões com medicamentos. Na minha opinião, para o aproveitamento dos estudos, é necessário que

busquemos em nós, força de vontade e a criação de um cronograma de estudos, acompanhado de hábitos

saudáveis, como uma boa alimentação e atividades

físicas". Essa pessoa sugeriu que esses medicamentos são oferecidos a nós através das indústrias

farmacêuticas, que fazem muitas propagandas para aumentar o consumo de medicamentos, ainda que eles estejam lucrando muito com isso.

André: Eu acho que isso não tem nada a ver. $\mathrm{O}$ medicamento foi criado para uma finalidade e é usado para outra, assim eu acho que a indústria farmacêutica não tem nenhuma responsabilidade em relação ao uso que se faz do medicamento, que não seja o correto.

(Masculino, 17).

Nicolas: Eu discordo, pois como todas as indústrias do mundo capitalista, esta também visa o lucro. Ou seja, a finalidade deveria ser curar as doenças, mas acaba sendo o lucro da indústria. E uma outra coisa,

há doenças que poderiam ser curadas, mas o lucro com um tratamento demorado é maior do que com um tratamento rápido que visa a cura. (Masculino, 18).

Germana: Por exemplo, se um medicamento para a cura do câncer tivesse comprovada sua eficácia e

fosse colocado no mercado, o lucro com tratamentos como a radioterapia e quimioterapia iria cair muito.

Isso faz com que sejam colocados no mercado mais medicamentos que vão manter as pessoas dependentes do que medicamentos que vão curá-las. (Feminino, 17).

Detectou-se uma concepção ingênua de um dos alunos sobre o poder da indústria farmacêutica, mas outro aluno o questionou e ao final puderam criar uma síntese dessas ideias. Seguiram-se mais comentários sobre os resultados.

Pesquisadora: Mais uma informação para vocês, os resultados da pesquisa ainda não estão prontos, mas o que eu notei até agora me diz que a maioria dos jovens, como vocês, nunca ouviu falar nesse tipo de medicamento, a maioria não conhece ninguém que faz 
uso desses medicamentos, mas eles acham legal e dizem que usariam. $\bigcirc$ que vocês acham disso?

André: Eu já vi um filme sobre esta temática, chama-se

"Sem limites". No filme o personagem consome uma substância que faz com que seu cérebro funcione a todo vapor durante 12 horas e neste intervalo ele pode fazer várias coisas, até aprender um novo idioma. Mas quando passa o efeito ele esquece o que ele tinha aprendido, e tem também vários efeitos colaterais como desidratação, e o desgaste físico. (Masculino, 17).

Fernando: Outra coisa, por mais que esse medicamento melhore a concentração, no momento em que eu estou estudando, ele não vai influenciar na minha capacidade de absorver este conhecimento. (Masculino, 18).

Para encerrar, houve a entrega de materiais informativos e o fechamento do grupo.

\section{Discussão}

Como já discutido, ingressar no ensino superior é o desejo da maioria dos alunos do ensino médio. Um estudo realizado em escolas públicas e privadas de 13 capitais brasileiras apontou como prioritário ingressar na universidade entre os alunos de todas as instituições, com uma frequência de respostas maior entre os alunos de escolas privadas (Abramovay \& Castro, 2003). A pesquisa de Sparta e Gomes (2005) confirma que o jovem tem atribuído grande importância ao ingresso na educação superior, seja aluno de escola pública ou privada. Os autores identificaram que essa seria a opção da maioria dos jovens pesquisados, em comparação com outras opções como fazer curso pré-vestibular, curso profissionalizante ou ingressar no mercado de trabalho. Um fato relevante na pesquisa foi que a escolaridade parental é uma variável de influência sobre a escolha dos jovens, visto que filhos de mães e pais com ensino superior foram os que mais escolheram a alternativa vestibular; filhos de mães e pais com ensino médio foram os que mais escolheram curso pré-vestibular; filhos de mães e pais com ensino fundamental foram os que mais escolheram curso profissionalizante e ingresso no mercado de trabalho.

Ingressar no ensino superior, além de ser o principal plano dos alunos para o futuro, é também a função que eles consideram mais importante na escola. No entanto, a prioridade dada a esse tipo de preparação acaba fazendo com que o conteúdo trabalhado seja somente aquele que é exigido dos alunos para o sucesso no processo seletivo de ingresso na educação superior, o que também pode reduzir o caráter mais humanístico e crítico dos conhecimentos ministrados. Em suma, ao proporcionar aos alunos um ensino voltado para a transmissão de conteúdos exigidos para a aprovação no vestibular, coloca-se em xeque a percepção da escola como um local de aprendizagem de valores e de socialização, uma arena privilegiada para a condução de uma formação para o exercício da cidadania que se apoie no desenvolvimento de uma consciência crítica, que capacite o aluno a intervir no meio social do qual faz parte, inculcando nele a importância do respeito ao próximo.

A percepção sobre a escola também pode ser influenciada pela própria cultura escolar, que atribui maiores expectativas de sucesso aos alunos das escolas privadas e menores aos alunos das escolas públicas. É um exemplo da cultura escolar a competitividade entre os alunos, exemplificada nos rankings a que eles são submetidos, ou o discurso de que 0 sucesso depende somente do esforço individual.

Uma pressão para obter bons resultados no vestibular pode levar os alunos a manifestarem vários sintomas. D'Ávila e Soares (2003) questionaram jovens a respeito do que despertava mais ansiedade frente ao vestibular, obtendo como resposta: medo da reprovação; excesso de matérias para estudar; razão desproporcional de candidato/vaga; despreparo em relação aos estudos; dificuldade da prova; cobrança dos pais, amigos e professores; incerteza quanto ao curso escolhido; inexperiência com o vestibular; falta de condições financeiras para cursar; falta de preparo para frequentar um curso universitário.

Essas dificuldades podem levar a outros problemas, como mostraram Paggiaro e Calais (2009), que encontraram manifestações de estresse em mais da metade $(67,7 \%)$ dos alunos de cursos pré-vestibulares. Os sintomas mais mencionados foram: sensação de desgaste físico constante; cansaço constante; problemas com a memória; pensamento constante sobre um só assunto; dúvidas 
quanto a si próprio; sensação de incompetência; tensão muscular; entre outros, sendo o vestibular a maior preocupação da amostra. Rocha et al. (2006) encontraram indicativos de transtorno depressivo entre estudantes do ensino médio de um colégio particular, com predomínio dos sintomas na amostra feminina. Os autores acreditam que os resultados foram reflexo de um estado de angústia, medos e confusões advindos da adolescência e da proximidade do exame vestibular.

Com isso, pode-se concluir que os alunos do ensino médio se sentem pressionados pelos pais e pela escola para obterem um bom resultado no vestibular, e essa pressão também pode levá-los ao consumo de medicamentos. As falas de alguns alunos dessa pesquisa são ilustrativas dessa situação:

Germana: (...) A gente tem a pressão de estar sempre preparado, de saber tudo. Acho que é por isso que alguns estudantes podem recorrer a esses medicamentos, principalmente os que não tem o hábito de estudar e deixam tudo para a última hora.

(Feminino, 17).

Fernando: (...) Acontece que por mais que você estude, não tem lugar para você lá. (Masculino, 18).

Uma percepção positiva acerca do aprimoramento cognitivo farmacológico pode condizer com uma crença cultural do sucesso a qualquer custo, onde elevados níveis de produtividade em curto prazo, com baixo investimento e alta qualidade, são imprescindíveis. Essa crença leva os alunos a pensarem que a aprovação no vestibular depende apenas do esforço individual, pois o "normal" é ter sempre um bom rendimento e, no final do ensino médio, ser aprovado no vestibular. Quando isso não acontece é porque há alguma coisa errada no cérebro desse estudante, e assim como as causas do insucesso estariam nele, a "cura" para o insucesso também estaria. Dessa forma, seria necessária apenas a administração do medicamento correto para voltar a funcionar adequadamente, pois o que está ruim precisa ficar bom e o que está bom sempre pode melhorar.

Os dados acima também indicam que a percepção positiva sobre os medicamentos pode ser considerada como uma tendência à automedicação, visto que medicamentos para aprimoramento cognitivo não são regulamentados no Brasil, e os alunos os obteriam por outros meios que não a prescrição médica. Nesse contexto, percebe-se que os índices de automedicação no Brasil são altos. Uma pesquisa do Instituto de Ciência, Tecnologia e Qualidade Industrial (2014) mostrou que a automedicação faz parte da rotina de $76,4 \%$ dos brasileiros, e entre jovens de 16 a 24 anos chega a 90,1\%. Cinco em cada dez carregam comprimidos para tomarem quando surge algum incômodo e 16,5\% usam analgésicos toda semana. A pesquisa também apontou que quanto maior a escolaridade, maior o consumo por conta própria, pois 50,9\% dos entrevistados com ensino fundamental compram medicamentos sem receita, enquanto $76,3 \%$ dos que têm ensino médio e $84,8 \%$ dos que têm ensino superior adotam a mesma prática.

Várias pesquisas confirmam a automedicação entre estudantes. Em relação ao público pré-universitário, a pesquisa de Cassimiro (2012) mostrou que $21 \%$ dos alunos dos dois cursos pré-vestibulares de Belo Horizonte (MG) pesquisados faziam uso de psicofármacos. As drogas antidepressivas foram as de maior incidência, mas $15 \%$ dos jovens afirmaram que usam drogas para TDAH, como o cloridrato de metilfenidato. Não houve diferença estatisticamente significativa entre as prevalências do uso de psicofármacos para os alunos de diferentes áreas de escolha para o vestibular, mas separando por área de interesse, verificou-se que a maioria dos usuários desejava ingressar em medicina, que é um curso bastante concorrido. Como já assinalado na introdução, no caso do público universitário, as drogas para aprimoramento cognitivo são mais populares, pois $94,23 \%$ dos estudantes de medicina do Centro Universitário de Volta Redonda (RJ) informaram já terem ouvido falar delas (Carneiro et al., 2013), e $35,5 \%$ dos estudantes da Universidade Federal da Bahia conheciam outros estudantes que faziam uso (Cruz et al., 2011).

Esses dados são preocupantes, primeiro, pela escassez de estudos longitudinais em médio e longo prazo que analisem os prejuízos associados ao uso indiscriminado da substância, e segundo porque, como Cesar e colaboradores (2012) pontuaram, foi verificada maior prevalência entre os usuários de metilfenidato e o risco no mínimo moderado para o desenvolvimento de dependência para álcool, 
anfetaminas e pelo menos uma droga ilícita. Pessoas com uso prévio de benzodiazepínicos, álcool ou anfetaminas também têm maiores chances de se tornarem usuários de metilfenidato.

Segundo o estudo realizado por Pasquini (2013) em 30 universidades do estado de São Paulo, 25,3\% dos estudantes alegaram que no período de provas ou quando julgam ser necessário adquirem a droga de origem paraguaia. Isso também traz 0 alerta de que aquisições ilegais do medicamento são ainda mais preocupantes, pois não se tem controle se a droga foi produzida dentro dos padrões reguladores exigidos pelos órgãos de fiscalização e vigilância em saúde. Essa droga adquirida no mercado negro também pode ser consumida para outras finalidades além do aprimoramento, como para recreação, o que assemelha o comportamento dos consumidores ao dos usuários das drogas ilícitas, também comuns dentro do sistema escolar e universitário.

No grupo focal, um dos alunos refletiu a esse respeito:

Lucas: Além disso, isso deve movimentar todo um mercado ilegal, porque sempre vai ter alguém para vender drogas; deve envolver muito dinheiro. (...) Eles só querem vender, e vender caro. (Masculino, 17).

Os estudantes também refletiram sobre o poder da indústria farmacêutica:

Nicolas: (...) Como todas as indústrias do mundo capitalista, esta (a indústria farmacêutica) também visa ao lucro. Ou seja, a finalidade deveria ser curar as doenças, mas acaba sendo o lucro da indústria. (...)

(Masculino, 18).

O consumo de substâncias psicoativas, em geral, é maior nas grandes cidades e nos centros mais desenvolvidos. Por exemplo, Cesar et al. (2012) encontraram maior consumo de medicamentos entre os estudantes universitários das regiões centro-oeste e sul do país. Isso ocorreria porque a população das megacidades, em virtude das desigualdades econômicas e sociais e do estresse ligado à acelerada urbanização, pode sofrer com a deterioração da sua saúde, particularmente da saúde mental, o que a predispõe a um maior consumo de medicamentos.
Esse foi um dos temas discutidos nos grupos focais, e quando instigados a falar sobre o assunto, os jovens inferiram que há um maior consumo de fármacos em cidades mais desenvolvidas, como pode ser observado na sequência de relatos:

Fernando: Acho que nas cidades maiores a pressão é maior. (...) Então você precisa ter essa preparação para se inserir no mercado de trabalho de forma muito mais rápida do que nas cidades menores. (Masculino, 18).

Heitor: A concorrência é grande tanto no vestibular quanto no mercado de trabalho, porque você precisa se destacar para ter seu lugar garantido. (Masculino, 17).

Fernando: (...) Se, por exemplo, uma pessoa dessas quer passar em um concurso, mas não consegue ter muita atenção nos estudos, pode ser que caia nessa de tomar esse tipo de remédio. (Masculino, 18).

Tsuda e Christoff (2015) também alertam que alguns estudantes podem fazer uso dessas substâncias pela curiosidade sobre elas e sua efetividade sobre as atividades físicas e mentais. Isso se reflete na fala de alunos desta pesquisa, que afirmaram não conhecer esses medicamentos, mas admitiram a possibilidade de usá-los, como mostra a fala abaixo:

Lucas: (...) As pessoas que estão se drogando para passar em tal curso, muito provavelmente não conhecem as consequências das coisas que estão tomando, conhecem apenas as vantagens. (...) Mas você nunca sabe se está de fato aprendendo (...). No meu caso eu não toparia fazer isso. Não gosto. Mas se eu estiver competindo com alguém que tomou e em quem esse medicamento funciona... (...) (Masculino, 17).

Nessa fala percebe-se que a pressão por resultados pode ser muito forte para algumas pessoas, originando o problema de consumo de medicamentos para melhorar o desempenho. Maher (2008) também mostrou nos resultados de sua pesquisa com cientistas de 60 países que os entrevistados se posicionavam no primeiro momento contra a oferta de medicamentos para crianças que não tinham deficiências. Contudo, cerca de um terço desses respondentes afirmaram que ficariam tentados em oferecer drogas a seus filhos, se descobrissem que os pais das demais crianças estivessem ofertando às deles para melhorar o desempenho. 
Petersen, Norgaard e Traulsen (2015), em entrevistas com alunos estadunidenses que fazem uso de estimulantes, identificaram neles características em comum: são ambiciosos, têm boas notas, são estudantes profissionais e em cursos de turno integral, têm muito tempo para atividades sociais e praticam atividade física algumas vezes por semana. Para eles o aprimoramento não seria para uma causa específica, mas para melhorar sua performance e se sentirem bem, como pode ser observado na fala: "Eu desejo ser o melhor e eu posso ser [...] Se você for responsável, se você se educar, se você não abusar dela, ela pode ser uma ferramenta útil [...]" (Estudante universitário estadunidense, 32 anos).

Os autores ainda afirmaram que muitos estudantes usuários tinham uma espécie de ritual quando iam usar o medicamento para estudar, que incluía organizar o ambiente, os livros, as anotações, o computador etc. antes de tomarem o medicamento. Eles faziam isso porque quando não se preparavam para a sessão de trabalho antes de o medicamento fazer efeito podiam perder horas com jogos de computador ou outras atividades de lazer, e que só aprenderam isso depois de perder tempo e o efeito da droga (Petersen, Norgaard \& Traulsen, 2015).

Para esses estudantes, a droga era vista como uma ajuda reservada para momentos importantes durante o semestre, quando surgiam sentimentos de desinteresse, sobrecarga e insegurança acadêmica e eles precisavam eliminar ou prevenir a procrastinação. O medicamento os transformava imediatamente de uma pessoa desinteressada, sobrecarregada e insegura, em outra produtiva, focada e confiante. Eles ainda afirmaram que tomavam não só para se livrar de algo desagradável, mas também para intensificar uma paixão ou entusiasmo que já estava lá, para ter prazer na experiência de estudar, como afirmou um estudante: "Adderal adiciona gasolina ao meu fogo" (Estudante universitário estadunidense, 23 anos) (Petersen, Norgaard \& Traulsen, 2015).

Liakoni, Schaub, Maier, Glauser e Liechti (2015), em pesquisa com estudantes estadunidenses de segundo grau, verificaram que aqueles que se sentiram mais pressionados pela escola ou mais estressados com o ambiente escolar foram os que mais revelaram terem usado substâncias para aprimoramento pelo menos uma vez no último ano, comparados a estudantes que não perceberam pressão da escola ou que perceberam uma pressão mínima. Os autores também averiguaram que os estudantes que usaram uma substância ao menos uma vez para aprimoramento cognitivo foram os que se sentiam menos satisfeitos com sua situação de vida, comparados aos não usuários.

Já em etapas posteriores da vida, Coelho (2014), em uma pesquisa desenvolvida com indivíduos envolvidos em atividades intelectuais tais como estudo para concurso público, conclusão de doutorado, seleção para pós-graduação no exterior, também encontrou nesse público uma percepção muito favorável aos medicamentos. Esses indivíduos procuraram a medicação com a finalidade de aumentar, seja em tempo e/ou qualidade, suas horas de estudo, e para isso buscaram médicos especialistas para obter uma prescrição. Eles relataram dificuldade para desempenhar atividades de estudo de acordo com suas expectativas, necessidades e as demandas sociais de desempenho, e por isso afirmaram sentir uma melhora na sua performance de estudo com o medicamento e declararam maior rendimento e ânimo para realizar as tarefas. Também é interessante pontuar que a prescrição médica trouxe segurança para esses indivíduos, pois a presença do médico foi vista como uma garantia no controle dos possíveis riscos que correm ao utilizarem um medicamento como esse.

A autora afirma que a produção de um desempenho mental de excelência, excedendo os limites da capacidade tida como normal, constitui a resposta para a demanda de uma sociedade competitiva e individualista, na qual exceder os próprios limites naturais é exceder o outro, o coletivo. Neste contexto, a fala de uma das entrevistadas da pesquisa de Coelho (2014) se mostra muito semelhante às encontradas nos jovens da presente pesquisa: "Via como uma potencialização dos estudos, para me sentir mais segura, aproveitar melhor o tempo, para manter-me acordada" (Coelho, 2014, p. 5).

Em consonância com esses dados, os participantes da pesquisa de Barros (2009) também afirmaram que $\circ$ bom desempenho nas tarefas e atividades profissionais é a principal fonte de reconhecimento social, o que justifica tanto esforço e investimento no desempenho cognitivo/acadêmico. Para eles, o 
reconhecimento social tanto estava relacionado ao desejo de a pessoa ser igual aos outros e, portanto, desejar ter o mesmo desempenho que os outros, quanto ao objetivo de diferenciar-se (destacar-se) deles. Para assemelhar-se ao grupo (sentimento de pertencimento), é necessário manter a individualidade, destacando-se do conjunto social.

A partir de todas essas informações, pode-se concluir que o uso não prescrito do metilfenidato é uma realidade em nosso país e não pode ser ignorado. Por isso, considerando o alto potencial de abuso e dependência do metilfenidato, torna-se urgente a realização de discussões que abordem a atual problemática do consumo indevido, alertando a população para o mau uso, os efeitos adversos já descritos e os ainda desconhecidos. Como observado, essa prática é disseminada visto que os estudos aqui citados mostraram dados de diversas localidades, e em diferentes níveis de ensino. Os dados encontrados também apontaram para a necessidade de mais investigações acerca da alta prevalência de uso a fim de propor medidas preventivas e/ou de oferecer apoio para os estudantes, com vistas a proporcionar uma melhor formação profissional sem riscos para a saúde.

No Brasil ainda se vive uma realidade que já foi superada há muito tempo em outros países, que é a universalização do ensino médio e o maior acesso ao ensino superior. Segundo a Pesquisa Nacional por Amostra de Domicílios (IBGE, 2015), ainda existem no Brasil 16,7\% dos jovens de 15 a 17 anos fora da escola. Entre os que estão na escola, 37,3\% estão atrasados em seu nível de ensino. Grande parte dos jovens considera a escola desmotivadora, sem sentido para sua vida e incompetente em lhe preparar para contribuir com o progresso da sociedade, seja por meio do ensino superior, seja na inserção no mercado de trabalho.

No entanto, quando a escola e o aluno atribuem apenas parcialmente o seu fracasso escolar à escola, recai sobre o estudante grande responsabilidade sobre seu sucesso escolar. Em uma sociedade em que a nota de aprovação no vestibular é mais importante que a apropriação do conhecimento, não se possibilita ao aluno que discuta o sentido do que está aprendendo, como está aprendendo e se está aprendendo. Isso pode levar a uma perda da den- sidade nos estudos, em face da oferta superficial de informações, onde o excesso de conhecimento fragmentado serve apenas para a realização de provas e avaliações e não para formar capacidade crítica. Essas práticas criam um sistema que pune e que expõe moralmente os alunos, quando valoriza os "melhores" e condena os "piores", tidos como mais ou menos inteligentes, respectivamente. Isso também leva ao aumento do sofrimento psíquico em função do sentimento de não pertença, de ser cobrado por mais êxito, somado ainda à culpa por não ser esforçado o suficiente e não ter a escolarização necessária para ocupar uma vaga no mercado de trabalho.

Algumas vezes, tanto as escolas quanto as próprias famílias projetam em suas crianças e adolescentes o desejo de que "sejam alguém na vida". Mas, ainda que a intenção seja boa, esse comportamento pode levar a pressões difíceis de serem vivenciadas pela criança e pelo adolescente. Além disso, podem existir contradições entre a realidade vivida e os planos para o futuro, incluindo uma vivência restrita da família com o estudo, ou o acesso limitado a uma escola de qualidade.

Todos esses fatores têm levado os alunos e a escola ao fracasso, pois entende-se por fracasso escolar o fato de um aluno, ao final de um período de escolarização determinado, não conseguir, por qualquer motivo, desempenhar as funções ou objetivos esperados para aquela etapa de formação. Em relação ao ensino médio, o fracasso escolar seria não conseguir prosseguir nos estudos, não estar preparado para o trabalho e a cidadania, não compreender os fundamentos científicos e tecnológicos e não estar aprimorado como pessoa humana, que são as finalidades do ensino médio preconizadas pela Lei de Diretrizes e Bases da Educação Nacional (1996).

Nessa concepção, o fracasso escolar seria fruto das relações que se estabelecem na escola, dos métodos e das condições de aprendizagem que são oferecidas aos alunos. As consequências do fracasso escolar seriam, por exemplo, crianças e adolescentes que não leem e nem escrevem com a fluência esperada, se mantêm com um baixo rendimento, têm histórico de múltiplas repetências, não prosseguem na escolarização, ou quando prosseguem não conseguem acompanhar, abandonam a escola antes de completarem sua formação, não se ajustam às 
regras institucionais, têm conduta indesejável, entre outros casos.

Em um estudo célebre, Patto (2015) constatou, a partir da análise minuciosa das histórias de vida e escolares de crianças pobres, que o fracasso escolar é construído nas relações sociais e educativas. A autora procedeu a uma análise genética das dificuldades escolares das crianças e concluiu que o fracasso escolar é um objeto social e dinâmico, engendrado historicamente e não intrínseco ao estudante.

Neste sentido, pode-se afirmar que o sucesso escolar também não seria intrínseco ao estudante, mas seria fruto das suas relações sociais e educativas. Posto isso, é necessário entender como a realidade educacional brasileira poderia levar alguns alunos a buscarem diferentes meios para atingirem sucesso escolar, o que não depende somente deles. É importante propor alternativas de intervenção com o intuito de prevenir a medicalização dos adolescentes voltada para o aprimoramento cognitivo farmacológico, o que poderia incluir debates nas salas de aula de ensino médio e nos cursinhos pré-vestibulares, trazendo à tona temas como os riscos envolvidos na prática, melhores estratégias de aprendizagem, além de promoção de espaços de fala para que possam dividir suas angústias e ansiedades frente ao vestibular. Além disso, podem ser realizadas outras atividades que envolvam toda comunidade escolar, como campanhas de conscientização, oficinas temáticas, grupos focais, discussão de filmes e textos etc.

Finalmente, é igualmente importante que essa discussão ocorra nas universidades. Primeiro porque se trata de um espaço em que a prática da medicalização tem muitos adeptos e cada aluno pode estar vulnerável a ela, e segundo porque os estudantes universitários são os futuros profissionais do país, e suas crenças sobre os medicamentos poderão influenciar suas práticas futuras, assim como sua saúde mental. Outro espaço que precisa ser ocupado por discussões é o espaço virtual, pois muitos são os sites e fanpages que propagam os possíveis efeitos benéficos dos fármacos. É necessário que haja mais páginas que divulguem os riscos do medicamento, com uma linguagem acessível e voltada para a população juvenil. Todas essas ações podem ser desenvolvidas pelos atores do espaço escolar como professores, diretores, coordenadores pedagógicos, orientadores educacionais, entre outros, em parceria com profissionais da área de saúde como psicólogos, médicos, enfermeiros e farmacêuticos.

\section{Conclusões}

Este texto apresentou uma reflexão sobre os desafios enfrentados pelos estudantes brasileiros de ensino médio que desejam ingressar no ensino superior. Sabe-se que o ensino superior não supre a necessidade de vagas demandadas pela população, o que leva a uma grande concorrência para o acesso a determinados cursos, particularmente os de maior prestígio e concorrência, e em determinadas instituições, sendo as públicas com maiores índices de interesse. Em virtude dessa competição, os alunos precisariam ter um desempenho alto no vestibular e no ENEM para conseguirem uma vaga na universidade.

ambiente escolar, sobretudo a universidade, também exige dos alunos um nível adequado de aprendizado, o que requer uma alta carga de trabalho e dedicação por parte deles. Nessas circunstâncias, estudantes saudáveis tornam-se propensos a utilizar substâncias psicoativas para estudarem durante mais tempo, aumentando o nível de energia e concentração e diminuindo a necessidade de descanso, criando expectativas de aperfeiçoar sua eficiência acadêmica.

Por ser esta uma prática que envolve riscos para a saúde física e mental, foi necessário entender melhor o que os jovens pensam a seu respeito. Os dados obtidos apontam que medicamentos para aprimoramento cognitivo são vistos pelos estudantes como algo positivo e que podem ser usados em situações diversas: às vésperas do vestibular; para ajudar nos momentos de pressão dos pais e da escola; quando se sentem sobrecarregados pelas suas atividades; para darem conta de múltiplas tarefas; para garantirem energia e concentração. No entanto, quando tiveram a oportunidade de pensar melhor sobre o tema e falar sobre os medicamentos nos grupos focais, os jovens conseguiram perceber os fatores envolvidos na adesão ao uso de substâncias e o que leva estudantes a consumi-las. 
Em razão do tema, até o momento ter sido pouco aprofundado no Brasil, e deste trabalho possuir caráter exploratório, a generalização dos seus resultados deve ser feita com cautela. Os dados coletados não são capazes de mostrar toda a diversidade de experiências, condições de vida, tradições, costumes, cultura e valores dos jovens, em virtude também da amostra de conveniência restrita. No entanto, seus resultados são coerentes com os apresentados em pesquisas nacionais e internacionais.

Para intervenções futuras coloca-se como recomendação a realização de grupos focais com universitários, a fim de se realizar uma comparação entre os resultados, bem como ampliar o debate sobre o tema na mídia, nas escolas, nos cursinhos e nas instituições de saúde, utilizando uma linguagem acessível aos estudantes, para que eles tenham ciência dos riscos envolvidos nessa prática.

\section{Conflitos de interesses}

Nenhum conflito financeiro, legal ou político envolvendo terceiros (governo, empresas e fundações privadas, etc.) foi declarado para nenhum aspecto do trabalho submetido (incluindo mas não limitandose a subvenções e financiamentos, conselho consultivo, desenho de estudo, preparação de manuscrito, análise estatística, etc).

\section{Referências}

Abramovay, M., \& Castro, M. G. (2003). Ensino médio: múltiplas vozes. Brasília: UNESCO, MEC.

Agência Nacional de Vigilância Sanitária. (2012). Inibidores de apetite no Brasil: reflexões sobre seu consumo nos anos de 2009 a 2011 . Boletim de Farmacoepidemiologia do SNGPC, 2(2), 1-14. Recuperado de: http://www.anvisa.gov.br/sngpc/ boletins/2012/boletim_sngpc_1_2012_modificado. pdf

Barros, D. B. (2009). Aprimoramento cognitivo farmacológico: grupos focais com universitários (Dissertação de mestrado). Instituto de Medicina Social, Universidade do Estado do Rio de Janeiro, Rio de Janeiro, RJ, Brasil. Recuperado de http://www.bdtd.uerj.br/ tde_arquivos/44/TDE-2012-05-11 1 1 50027Z-2273/ Publico/Denise\%20Borges\%20Barros-Dissertacao.pdf
Carneiro, S. G., Prado, A. S. T., Moura, H. C., Strapasson, J. F., Rabelo, N. F., Ribeiro, T. T., \& Jesus, E. C. (2013). O uso não prescrito de metilfenidato entre acadêmicos de medicina. Cadernos UniFOA, 8(1), 53-59. Recuperado de http://revistas.unifoa.edu.br/index.php/cadernos/ article/view/87

Cassimiro, E. E. (2012). Frequência do uso de psicofármacos entre jovens estudantes que cursam pré-vestibular. Adolescência \& Saude, 9(4), 27-36. Recuperado de http://www.adolescenciaesaude.com/detalhe_artigo. asp?id $=342$

Cesar, E. L. R., Wagner, G. A., Castaldelli- Maia, J. M., Silveira, C. M., Andrade, A. G., \& Oliveira, L. G. (2012). Uso prescrito de cloridrato de metilfenidato e correlatos entre estudantes universitários brasileiros. Revista de Psiquiatria Clínica, 39(6), 183-1 88. Recuperado de http://www.scielo.br/ pdf/rpc/v39n6/01.pdf. doi: 10.1590/S0101$\underline{60832012000600001}$

Coelho, E. B. (2014). Psicofármaco e sua Magia: metilfenidato e performance. Reunião Brasileira de Antropologia, Natal, RN, Brasil, 29.

Recuperado de http://www.29rba.abant.org.br/ resources/anais/1/1401982362_ARQUIVO_ EleonoraCoelhoRBA 14.pdf

Cruz, T. C. S. C., Barreto Junior, E. P. S., Gama, M. L. M., Maia, L. C. M., Melo Filho, M. J. X., Manganotti Neto, O., \& Coutinho, D. M. (2011). Uso não-prescrito de metilfenidato entre estudantes de medicina da Universidade Federal da Bahia. Gazeta Médica da Bahia, 81(1), 3-6. Recuperado de http://www. gmbahia.ufba.br/index.php/gmbahia/article/ viewFile/1 148/1082

D'Ávila, G. T., \& Soares, D. H. P. (2003). Vestibular: fatores geradores de ansiedade na "cena da prova". Revista brasileira de orientação profissional, 4(1/2), 105-1 16. Recuperado de http://pepsic.bvsalud.org/pdf/rbop/ v4n1-2/v4n1-2a10.pdf

Farah, M. J., \& Wolpe, P. R. (2004). Monitoring and Manipulating Brain Function: New Neuroscience Technologies and Their Ethical Implications. Hastings Center Report, 34(3), 35-45. Recuperado de https:// www.ncbi.nlm.nih.gov/pubmed/15281725

Gondim, S.M.G. (2003). Grupos focais como técnica de investigação qualitativa: desafios metodológicos. Paidéia, 12(24), 149-161. Recuperado de http:// www.scielo.br/pdf/paideia/v1 2n24/04.pdf. doi: 10.1590/S0103-863X2002000300004 
Greely, H, Sahakian, B., Harris, J., Kessler, R. C., Gazzaniga, M., Campbell, P., \& Farah, M. J. (2008). Towards responsible use of cognitive-enhancing drugs by the healthy. Nature, 456, 702-705. Recuperado de https://www.nature.com/articles/456702a.pdf. doi: $10.1038 / 456702 a$

Instituto Brasileiro de Geografia e Estatística (2015). Pesquisa Nacional por Amostra de Domicílios. Recuperado de https://ww2.ibge.gov.br/home/estatistica/pesquisas/ pesquisa_resultados.php?id_pesquisa $=40$

Instituto de Ciência, Tecnologia e Qualidade Industrial. (2014). Pesquisa - Automedicação no Brasil. Recuperado de: http://www.ictq.com.br/pesquisa-doictq/353-indicacao-de-amigo-reforca-a-pratica-daautomedicacao

Lei $n^{\circ}$ 9.394. (1996, 20 de dezembro). Estabelece as Diretrizes e Bases da Educação Nacional. Recuperado de http://www.planalto.gov.br/ccivil_03/Leis/19394. $\mathrm{htm}$

Liakoni, E., Schaub, M.P., Maier L. J., Glauser, G. V., \& Liechti, M. E. (2015). The Use of Prescription Drugs, Recreational Drugs, and "Soft Enhancers" for Cognitive Enhancement among Swiss Secondary School Students. PLoS One, 27(10), 1-12. Recuperado de http:// journals.plos.org/plosone $/$ article $/$ file?id=10.1371/ journal.pone.0141289\&type =printable. doi: 10.1371 /iournal.pone.0141289

Machado, L. C., \& Toma, M. A. (2016). Qual a verdadeira função do metilfenidato na memória de indivíduos saudáveis? Revista UNILUS Ensino e Pesquisa. 13(30), 126-130. Recuperado de http://revista. unilus.edu.br/index.php/ruep/article/view/706/ u2016v13n30e706

Maher, B. (2008). Poll results: look who's doping. Nature, 452, 674-675. Recuperado de https://www.nature. $\mathrm{com} /$ news/2008/080409/full/452674a.html. doi: $10.1038 / 452674 a$

Paggiaro, P. B. S., \& Calais, S. L. (2009). Estresse e escolha profissional: um difícil problema para alunos de curso pré-vestibular. Contextos clínicos, 2(2), 97-105. Recuperado de http://pepsic.bvsalud.org/pdf/cclin/ v2n2/v2n2a04.pdf. doi: 10.4013/ctc.2009.22.04

Pasquini N.C. (2013). Uso de metilfenido (mfd) por estudantes universitários com intuito de "turbinar" o cérebro. BioFar - Revista Biologia e Farmácia, 9(2), 107-113.

Patto, M. H. S. (2015). A produção do fracasso escolar: histórias de submissão e rebeldia. São Paulo: Intermeios.
Petersen, M. A., Nørgaard, L. S., \& Traulsen, J. M. (2015). Pursuing Pleasures of Productivity: University Students' Use of Prescription Stimulants for Enhancement and the Moral Uncertainty of Making Work Fun. Cult Med Psychiatry, 39(4), 665-679. Recuperado de https:// www.ncbi.nlm.nih.gov/pubmed/25956594. doi: $10.1007 /$ s $11013-015-9457-4$

Rocha, T. H. R., Ribeiro, J. E. C., Pereira, G. A. Aveiro, C. C., \& Silva, L. C. A-M. (2006). Sintomas depressivos em adolescentes de um colégio particular. Psico-USF, 11 (1), 95-102. Recuperado de http://www.scielo. $\mathrm{br} / \mathrm{pdf} / \mathrm{pusf} / \mathrm{v} 1 \mathrm{ln} 1 / \mathrm{v} 1 \mathrm{ln} 1 \mathrm{a} 11$.pdf. doi: $10.1590 /$ S1413-82712006000100011

Schmidt, M. L. S. (2006). Pesquisa participante: alteridade e comunidades interpretativas. Psicologia USP, 17(2), 1 1-41. Recuperado de http://www.scielo.br/pdf/ pusp/v17n2/v17n2a02.pdf. doi: 10.1590/S0103$\underline{65642006000200002}$

Sparta, M., \& Gomes, W. B. (2005). Importância atribuída ao ingresso na educação superior por alunos do ensino médio. Revista brasileira de orientação profissional, 6(2), 45-53. Recuperado de http://pepsic.bvsalud. org/pdf/rbop/v6n2/v6n2a05.pdf

Trigueiro, E. S. O. (2017). Adolescentes, o aprimoramento cognitivo farmacológico e o acesso ao ensino superior (Tese de Doutorado). Instituto de Psicologia, Universidade de São Paulo, São Paulo, SP, Brasil. Recuperado de http://www.teses.usp.br/teses/ disponiveis/47/47131/tde-13122017-085844/

Tsuda, C. A., \& Christoff, A. O. (2015). Avaliação do padrão de uso de estimulantes em uma faculdade de Curitiba - PR. Caderno da escola de saúde, 1(13), 116-132. Recuperado de http://portaldeperiodicos. unibrasil.com.br/index.php/cadernossaude/article/ view $/ 2433 / 2003$. 